\title{
Design of High Strength and Lightweight Construction Composites Using Advanced Porous and Tough Cementitious Materials
}

\author{
Hongda Guo ${ }^{1}$, Qing Liu ${ }^{1}$, Jianyu $\mathrm{Xu}^{1}$ and Guoxing Sun ${ }^{2 *}$
}

\begin{abstract}
High-strength and lightweight are two of the most important parameters for composites in the construction field. Here, we developed a novel foam concrete structure with sandwich porous structure by using in-situ polymerized polyacrylamide and ultra-stable foam, which can obtain higher mechanical strength in comparison to the normal porous concrete with the same density. The ratio of stiffness to weight was maximized to achieve the optimal sandwich porous structure size. The SEM images showed that the interface bond between the foam concrete and the polymer modified cement paste was tight and robust. The flexural strength of the novel structure was $65.6 \%$ higher than that of the foamed concrete at the same density. The series model was established to calculate the composite thermal conductivity of the novel foam concrete structure, indicating that the heat insulation was slightly improved compared with the normal foam concrete. Moreover, water resistance displayed a slight increase by constructing this sandwich porous structure. Hopefully, the novel composite with sandwich porous structure can put a new way for designing the lightweight and high strength insulation thermal structure.
\end{abstract}

\section{Introduction}

Composite structure with alternative porous and solid components is the result of biological evolution. In the biological evolution process, sandwich porous structures have been developing excellent mechanical properties and functional benefits, for example, the human skull (Meyers et al. 2008). The skull bone has a typical ultralight sandwich porous structure consisting of compact bone and cancellous bone, which has attracted lots of attention from researchers (Chen et al. 2012; Gibson 2005; Huebsch and Mooney 2009; Xiong et al. 2015; Zheng et al. 2015). Sandwich porous structures are multilayered composite structures, which can be optimized to achieve the expected loading conditions and service life (Birman and Kardomateas 2018). These structures are constructed by two stiff surface layers and a low density panel core added between them (Xiong et al. 2019). Compared with the monolithic design structure, sandwich porous structure can increase the bending stiffness of the structure without sacrificing the weight, while improving the energy absorption and shock resistance (Sennewald et al. 2014). In the sandwich porous structure, the panel is mainly loaded with compression

${ }^{1} \mathrm{Ph} . \mathrm{D}$. Student, Joint Key Laboratory of the Ministry of Education, Institute of Applied Physics and Materials Engineering, University of Macau, Avenida da Universidade, Taipa, Macau SAR, China.

${ }^{2}$ Assistant Professor, Joint Key Laboratory of the Ministry of Education, Institute of Applied Physics and Materials Engineering, University of Macau, Avenida da Universidade, Taipa, Macau SAR, China.

*Corresponding author, E-mail: gxsun@um.edu.mo and tension, and the inner core is mainly loaded with compression and shear force. The purpose of designing the sandwich porous structure is to reduce the dead weight, improve the mechanical strength and maintain structural integrity, which can be achieved by selecting materials and spatial arrangement (Birman and Kardomateas 2018; Sun et al. 2018b). Therefore, the sandwich porous structure can be an excellent lightweight and high strength structure.

Sandwich porous structures have been utilized in many industries owing to their excellent properties. For instance, in the aerospace field, aircraft and sandwich shield are sandwich structures (Arunkumar et al. 2017; Cherniaev and Telichev 2017). And for high performance lithium ion batteries and energy harvesters, sandwich porous structure plays a major advantage $(\mathrm{Qu}$ et al. 2018; Tummala et al. 2017; Zeng et al. 2017). Similarly, in the field of building materials, the sandwich structures are usually applied to realize various functions (Bach et al. 2017; Chróścielewski et al. 2017; Hopkins et al. 2017; Pascual et al. 2017; Tabatabaiefar et al. 2017). In the application of lightweight and high strength wallboards, light materials were poured into hard shells to form a sandwich porous structure. However, the bonding strength between two materials was very low and the fabricate process was complicate, limiting its application in the construction structures (Liu and Tian 2012). Thus, material selection, structural design and manufacturing process are very important in the application of sandwich porous structure.

In this study, polymer modified cement paste and ultra-stable foamed concrete were selected to manufacture the novel foam concrete sandwich porous structure. The surface layer of the sandwich porous structure was made of polymer modified cement paste in order to improve 
the flexural strength. The inner core of the sandwich porous structure can be made of ultra-stable foamed concrete which has a narrow pore size distribution and a high strength. In the design of the structure, the maximum ratio of stiffness to weight was followed to determine the size of the structure. Different from the process of pouring light material in the hard shell, the sandwich porous structure in this study was constructed by layered pouring. The interface of sandwich porous structure was characterized by scanning electron microscopy (SEM). The mechanical properties, thermal conductivity and water absorption of the sandwich porous structure and ultra-stable foamed concrete were tested.

\section{Materials and methods}

\subsection{Materials}

The inner core of the sandwich porous structure is ultra-stable foamed concrete, made of ultra-stable foam and cement slurry. The cement used in the experiment was Macao standard P•I 52.5 Portland cement produced in Macao. Synthetic surfactants were used as foam agent to produce foamed concrete. The surface layer of the sandwich porous structure is the polymer modified cement paste, made of polymer and cement slurry. The polymer was synthesized by and in situ polymerization of acrylamide under the catalysis of $\mathrm{N}, \mathrm{N}, \mathrm{N}$ ',N'-Tetramethylethylenediamine. Acrylamide (AM, $\mathrm{C}_{3} \mathrm{H}_{5} \mathrm{NO}, \mathrm{AR}, 99.0 \%$ ), Ammonium persulfate (APS, ACS reagent, $\geq 98.0 \%$ ) and $\mathrm{N}, \mathrm{N}, \mathrm{N}^{\prime}, \mathrm{N}^{\prime}-$ Tetramethylethylenediamine (TEMED, $\geq 99.5 \%$ ) were used.

\subsection{Design of structure}

When determining the section size, the principle of high stiffness and light weight was adopted. Considering the times of the term in the formula and the importance of the overall weight of the structure, the ratio of stiffness to the fourth power of weight was solved to obtain the best section size. Figure 1 is the schematic diagram of the cross section. The upper and lower layers were not differentiated in use, so the design size was the same.

The moment of inertia of the rectangular section is

$$
I_{z}=\frac{b h^{3}}{12}
$$

Then the moment of inertia of the upper and lower layers and the middle layer are

$$
\begin{aligned}
& I_{1}=\frac{b}{12}\left[\left(2 h_{1}+h_{2}\right)^{3}-h_{2}^{3}\right]=\frac{b}{12}\left(8 h_{1}^{3}+12 h_{1}^{2} h_{2}+6 h_{1} h_{2}^{2}\right) \\
& I_{2}=\frac{b}{12} h_{2}^{3}
\end{aligned}
$$

The equivalent stiffness of the section is

$$
(E I)_{e q}=E_{1} I_{1}+E_{2} I_{2}
$$

where $E_{1}$ is the elastic modulus of the upper and lower layers, and $E_{2}$ is the elastic modulus of the middle layer.

Through the results of these studies (Eltayeb et al. 2020; Li et al. 2017; Lura et al. 2003; Rasa et al. 2009; Zhang and Wang 2016), and there's

$$
\begin{aligned}
& E_{1}=3 E_{2} \\
& \rho_{1}=3 \rho_{2}
\end{aligned}
$$

The weight of the structure is

$$
M=\left(2 b h_{1} \rho_{1}+b h_{2} \rho_{2}\right) \times L
$$

where $L$ is the structure length.

Assuming that $h_{2}=x h_{1}$.

Then the ratio of stiffness to the fourth power of weight is,

$$
E I / M^{4}=\frac{\frac{E 2 b h_{1}^{3}}{12}\left[3\left(8+12 x+6 x^{2}\right)+x^{3}\right]}{\left(b h_{1} \rho_{2} L\right)^{4} \cdot(6+x)^{4}}=A \cdot \frac{3\left(8+12 x+6 x^{2}\right)+x^{3}}{(6+x)^{4}}
$$

where, $A$ is constant value, which does not affect the acquisition of $x$ value corresponding to the peak value.

$$
A=\frac{E_{2}}{12 b^{3} h_{1} \rho_{2}^{4} L^{4}}
$$

By solving formula (8), we can get that $x=6$ is the optimal solution.

The relation between $h_{1}$ and $h_{2}$ is

$$
h_{2}=6 h_{1}
$$

(a)

(b)

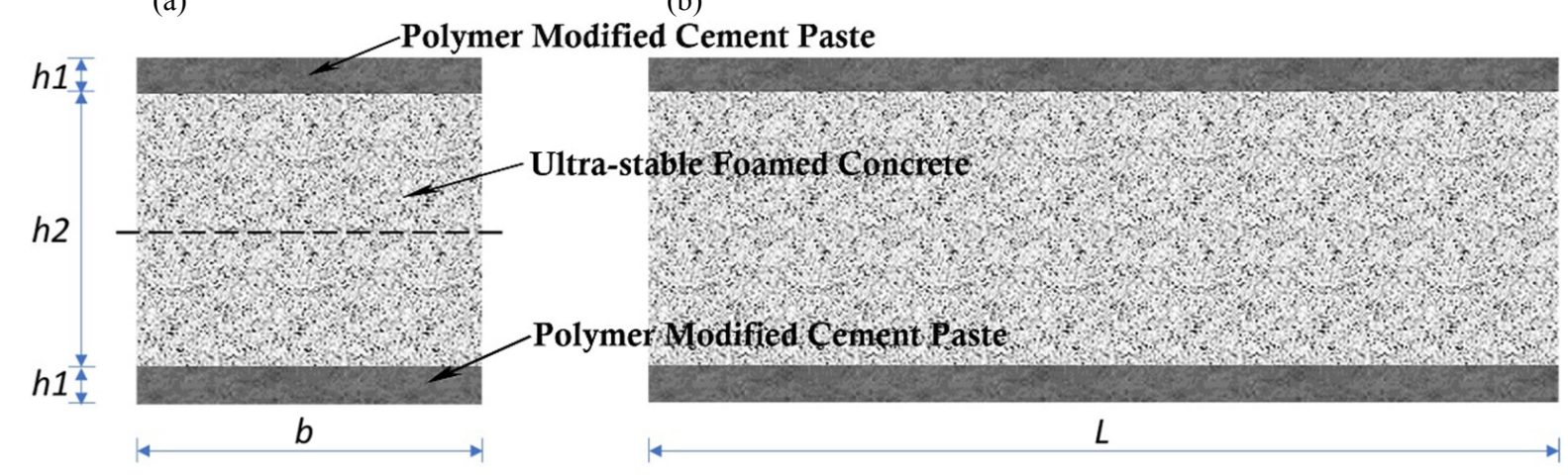

Fig. 1 Cross section diagram of the sandwich porous structure: (a) front view (b) right view. 
Table 1 Mix proportions of sandwich porous structure and ultra-stable foamed concrete.

\begin{tabular}{cccccccccc}
\hline \multirow{2}{*}{ Type } & Mix & $\begin{array}{c}\text { Cement } \\
(\mathrm{kg})\end{array}$ & $\begin{array}{c}\text { Water } \\
(\mathrm{kg})\end{array}$ & $\begin{array}{c}\text { Foam } \\
(\mathrm{m} 3)\end{array}$ & $\begin{array}{c}\text { AM } \\
(\mathrm{kg})\end{array}$ & $\begin{array}{c}\text { APS } \\
(\mathrm{g})\end{array}$ & $\begin{array}{c}\text { TEMED } \\
(\mathrm{mL})\end{array}$ & $\begin{array}{c}\text { Density } \\
(\mathrm{kg} / \mathrm{m} 3)\end{array}$ & $\begin{array}{c}\text { Average density } \\
(\mathrm{kg} / \mathrm{m} 3)\end{array}$ \\
\hline \multirow{2}{*}{$\mathrm{SPS}^{1}$} & $\mathrm{PMC}^{3}$ & 1167 & 584 & - & 1.17 & 8.57 & 3.11 & $1500 \pm 10$ & \multirow{2}{*}{$750 \pm 10$} \\
\cline { 2 - 8 } & $\mathrm{UFC}^{3} 500^{4}$ & 350 & 175 & 0.7 & - & - & - & $500 \pm 10$ & \\
\hline $\mathrm{UFC}^{2}$ & $\mathrm{UFC}^{2} 750^{5}$ & 538 & 269 & 0.538 & - & - & - & $750 \pm 10$ & $750 \pm 10$ \\
\hline
\end{tabular}

${ }^{1} \mathrm{SPS}=$ Sandwich Porous Structure; ${ }^{2} \mathrm{UFC}=$ Ultra-stable Foamed Concrete $;{ }^{3} \mathrm{PMC}=$ Polymer Modified Cement Paste; ${ }^{4} \mathrm{UFC}-500$ $=$ Ultra-stable Foamed Concrete with a density of $500 \mathrm{~kg} / \mathrm{m}^{3} ;{ }^{5} \mathrm{UFC}-750=$ Ultra-stable Foamed Concrete with a density of 750 $\mathrm{kg} / \mathrm{m}^{3}$.

Table 2 Mix proportions of polymer modified cement paste and plain cement paste.

\begin{tabular}{cccccc}
\hline Type & Cement $(\mathrm{kg})$ & Water $(\mathrm{kg})$ & AM $(\mathrm{kg})$ & APS $(\mathrm{g})$ & TEMED $(\mathrm{mL})$ \\
\hline PMC $^{1}$ & 1167 & 584 & 1.17 & 8.57 & 3.11 \\
\hline PCP $^{2}$ & 1167 & 584 & - & - & - \\
\hline
\end{tabular}

${ }^{1} \mathrm{PMC}=$ Polymer Modified Cement Paste $;{ }^{2} \mathrm{PCP}=$ Plain Cement Paste.

The sample thickness in this study was $40 \mathrm{~mm}$, so the thickness of the upper and lower layers was $5 \mathrm{~mm}$, while the thickness of the middle layer is $30 \mathrm{~mm}$.

\subsection{Methods}

\subsubsection{Preparation of polymer modified cement} paste

The chemicals were added to the water and stirred magnetically for ten minutes to obtain the transparent aqueous solution. Then, the cement was mixed at a low speed with a blender for 3 minutes. During the mixing process, water containing acrylamide (AM) monomers was added, and the water-cement ratio was 0.5 . After that, the mixed cement slurry was poured into the mold with a size of $160 \mathrm{~mm} \times 40 \mathrm{~mm} \times 40 \mathrm{~mm}$ to fabricate sandwich porous structure, and the thickness of the polymer modified cement paste layer was $5 \mathrm{~mm}$. The mix proportion is listed in Table 1. The polymer modified cement paste and plain cement paste with a water-cement ratio of 0.5 were also prepared to do the flexural strength test and the mix proportion was listed in Table 2.

\subsubsection{Preparation of ultra-stable foamed concrete}

The ultra-stable foamed concrete is made of ultra-stable foams and cement slurry. Water was added and mixed with cement to make cement slurry with a water-cement ratio of 0.5 . Ultra-stable foams are made of synthetic surfactants and are stable, independent and small in diameter. The synthetic surfactant consists of a surfactant, mainly sodium dodecyl sulfate or sodium dodecylbenzene sulfonate, and nanoparticles, generally smaller than $50 \mathrm{~nm}$ in diameter. The results of Sun et al. (2018a) show that the ultra-stable foamed concrete has a narrower pore size distribution, fewer connected pores, higher compressive strength and lower drying shrinkage. Therefore, the ultra-stable foamed concrete was chosen as the sandwich porous structure inner core and the control group. The fresh foam produced by the foaming machine was poured to the cement slurry and mixed evenly to reduce the damage of foam. Then, the well-mixed cement slurry was cast into the mold with a size of $160 \mathrm{~mm}$ $\times 40 \mathrm{~mm} \times 40 \mathrm{~mm}$ to make sandwich porous structure, and the thickness of the ultra-stable foamed concrete layer is $30 \mathrm{~mm}$. After the sample was placed at a room temperature for 48 hours, demolded and put into the curing box with a temperature of $20 \pm 2^{\circ} \mathrm{C}$ and a relative humidity of $95 \%$ for 28 days.

\subsubsection{Interface processing}

The layered pouring method was adopted to fabricate the novel foam structure. First, the bottom layer of the polymer modified cement paste was poured. After two hours, the ultra-stable foamed concrete (intermediate layer) was cast, and the polymer modified cement paste (top layer) was poured in another two hours. At the same time, the interface between two materials was ornamented by physical methods, to improve the bonding performance.

\subsubsection{Flexural strength}

After curing, samples were taken out from the curing box and put on an oven at $60^{\circ} \mathrm{C}$ to dry until the constant weight was reached. MTS Test Works was used to test the flexural strength of the samples. The flexural strength was tested by three-point bending with the loading rate of $0.01 \mathrm{~mm} / \mathrm{s}$. After the weight of the sample was constant, the dry density of the sample was calculated according to China Standard JG/T 266-2011 (2011).

\subsubsection{Water absorption}

After curing for 28 days, the sample was placed in an oven of $60^{\circ} \mathrm{C}$ and dried until the weight of the sample was constant. After the sample was cooled, it was put into a container of $20^{\circ} \mathrm{C}$. Water was added in a gradient and kept for a corresponding time. After water absorption, the sample was taken out of the water, wiped the surface water and weighed. The water absorption rate $W_{R}$ was determined according to China Standard JG/T 266-2011 and calculated by formula (11) (China JG/T 266-2011 2011).

$$
W_{R}=\frac{m_{g}-m_{o}}{m_{o}} \times 100
$$


In the formula, $m_{o}$ is the mass of the specimen after drying, and $m_{g}$ is the mass of the specimen after water absorption, both in grams.

\subsubsection{Thermal conductivity}

Samples were dried to the constant weight before conducting the thermal conductivity test. DRE-2C thermal conductivity tester was performed to test the samples. The principle was transient plane source method. The novel foam concrete structure is a composite structure. Herein, the thermal conductivity of composite structure can be obtained by Generalized self-consistent model, Krischer and Kroll model, the Parallel model, the Series model and Maxwell model (Lee et al. 2006; Meshgin and Xi 2013; Nan et al. 1997; Taoukil et al. 2013). For the sandwich porous structure, there are two directions of thermal conductivity, which are vertical and horizontal, respectively, as shown in Fig. 2. In general, the thermal conductivity perpendicular to the surface direction is used for sandwich porous structure. Therefore, the series model was used to calculate the composite thermal conductivity.

The thermal conductivity of each layer was tested separately, and then the formula for calculating the thermal conductivity of the composite structure was applied to get the composite thermal conductivity of the sandwich structure. The calculation formula is as follows:

Firstly, the thermal resistance $R_{i}$ of monolayer structure is

$$
R_{i}=\delta_{i} / K_{i}
$$

where, $R_{i}\left(K \cdot m^{2} \cdot W^{1}\right)$ is the thermal resistance of monolayer structure. $\delta_{i}(m)$ is the thickness of a monolayer structure. $K_{i}\left(W \cdot m^{-1} \cdot K^{-1}\right)$ is the thermal conductivity of monolayer structure.

According to the calculation method of multilayer serial structure, the total thermal resistance $R$ is the sum of the thermal resistance of each single-layer structure:

$$
R=\sum_{i=1}^{n} R_{i}=\sum_{i=1}^{n} \frac{\delta_{i}}{K_{i}}
$$

Assuming that the total thickness of the multilayer structure is $\delta$ and the composite thermal conductivity is $K$, the total thermal resistance $R$ is
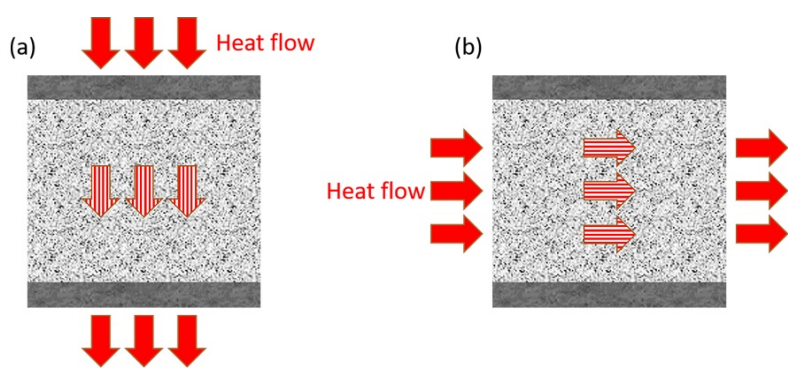

Fig. 2 Two directions of thermal conductivity: (a) vertical direction, (b) horizontal direction.

$$
R=\frac{\delta}{K}
$$

In combination with formulas (13) and (14), the composite thermal conductivity $K$ of the multilayer serial structure is obtained as

$$
K_{s}=\frac{\sum_{i=1}^{n} \delta_{i}}{\sum_{i=1}^{n} \frac{\delta_{i}}{K_{i}}}
$$

The thermal conductivity of sandwich porous structure is calculated by formula (15).

\subsubsection{Scanning electron microscopy}

Sample preparation involves drying and gold spraying. After curing for 28 days, the sample was placed in an oven of $60^{\circ} \mathrm{C}$ for 24 hours. Then, the samples were sprayed with gold and analyzed using FESEM (Zeiss Sigma) with an accelerating voltage of $5 \mathrm{~V}$.

\section{Results and discussion}

\subsection{Structure and microstructure}

The macroscopic structure and microscopic structure of sandwich porous structure are equally important to analyzing the interface. Figure 3 is the optical image of the sandwich porous structure. It can be seen that the bottom and top sides of the novel foam concrete structure were cement paste layers modified by polymer, which were hard and dense, and the inner core was light and porous ultra-stable foamed concrete, which tightly bonded with the polymer modified cement paste. More importantly, the distribution of pores in the ultra-stable foamed concrete layer was homogeneous.

The scanning electron microscopy (SEM) images (Fig. 4) were employed to show the interface of sandwich porous structure. The surface of the polymer modified cement paste layer (Fig. 4a) was compact and had a higher density and a higher strength. Therefore, the polymer modified cement layer acted as the surface layer

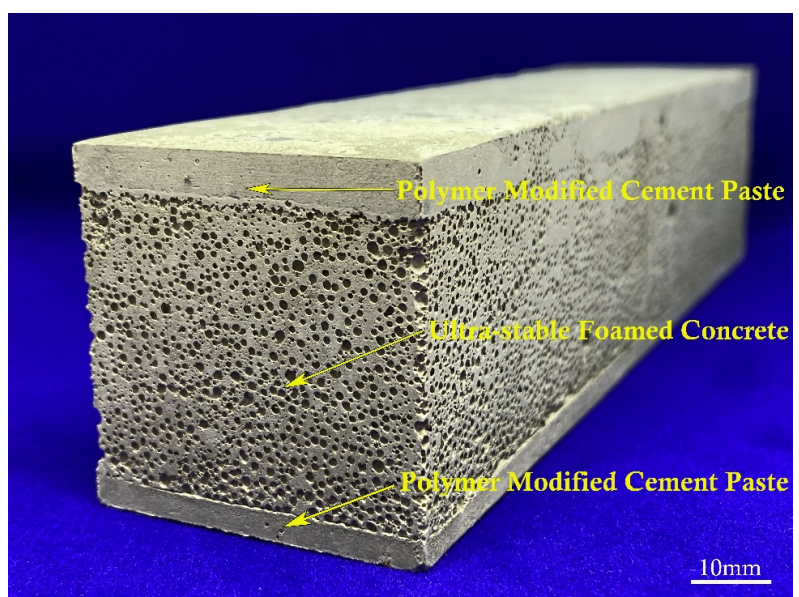

Fig. 3 An optical image of the sandwich porous structure. 
of the sandwich porous structure, bearing greater stress and reducing water absorption. The surface of the ultra-stable foamed concrete layer (Fig. 4c) was porous and had a lower density. Therefore, the ultra-stable foamed concrete layer acted as an inner core of the sandwich porous structure, reducing the overall weight and preventing heat transfer. Figure $\mathbf{4 b}$ shows the interface between ultra-stable foamed concrete and polymer modified cement paste. The interface bond was continuous and tightly connected due to interface processing. The layered pouring method was adopted to fabricate the novel foam structure before the acceleration period of the next layer hydration process, and the viscosity of the polymer modified cement paste can provide the bonding strength for the interface between ultra-stable foamed concrete and polymer modified cement paste. Therefore, the interface had good bond strength and would not crack under load

\subsection{Flexural strength}

The flexural strength of polymer modified cement paste and plain cement paste were shown in Fig. 5. The 28-day flexural strength of polymer modified cement paste was 14.12 $\mathrm{MPa}$, which was $46.9 \%$ higher than the 28 -day flexural strength of plain cement paste, demonstrating that the flexural strength of the polymer modified cement paste was greatly increased. The polymer modified cement paste works by suppressing the phase index, so that the polymer chains are separated from each other, and the cement is distributed around the chain without slipping. When the samples carries the load, the polymer chain can inhibit the formation of cracks, thus improving the flexural strength of the cement paste (Liu et al. 2020).

Falliano et al. (2019) used the protein-based foaming agent and measured the flexural strength of foam concrete with a density of $611 \mathrm{~kg} / \mathrm{m}^{3}$ at a water-cement ratio of 0.3, which was 1.09 MPa. Soleimanzadeh et al. (2013) reported the flexural strength of foam concrete with a density of $800 \mathrm{~kg} / \mathrm{m}^{3}$ was less than 0.5 . In this study, ultra-stable foamed concrete with better flexural strength was used as the control group. The density of sandwich porous structure and ultra-stable foamed concrete were both $750 \mathrm{~kg} / \mathrm{m}^{3}$. Figure 6 displays the flexural strength of the novel foam concrete structure and the ultra-stable foamed concrete with the same dry density. At different curing ages, the flexural strength of sandwich porous structure was much higher than that of ultra-stable foamed concrete. The 7 days flexural strength of sand-
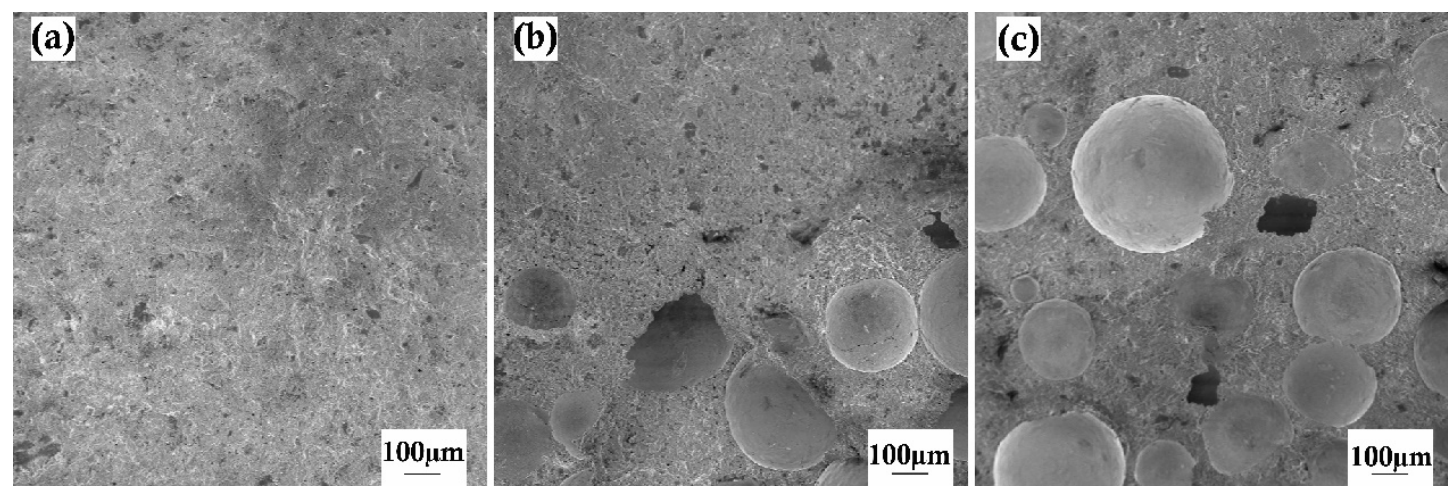

Fig. 4 SEM images of the sandwich porous structure: (a) Polymer modified cement paste layer (1 wt\% AM), (b) Sandwich porous structure interface, (c) Ultra-stable foamed concrete layer (density: $500 \mathrm{~kg} / \mathrm{m}^{3}$ ).

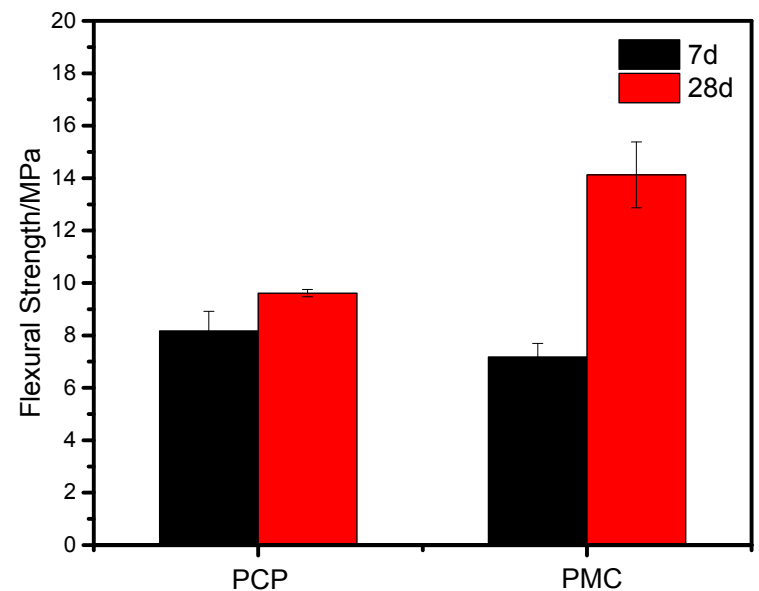

Fig. 5 Flexural strength of the polymer modified cement paste. $\mathrm{PCP}=$ Plain Cement Paste; $\mathrm{PMC}=$ Polymer Modified Cement Paste (1 wt $\%$ AM).

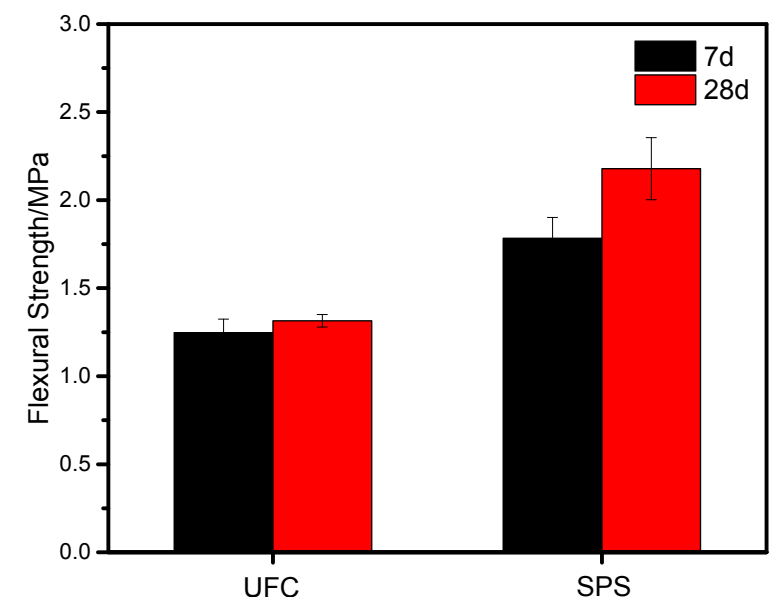

Fig. 6 Flexural strength of the sandwich porous structure. UFC = Ultra-stable Foamed Concrete (density: 750 $\mathrm{kg} / \mathrm{m}^{3}$ ); SPS= Sandwich Porous Structure (density: 750 $\mathrm{kg} / \mathrm{m}^{3}$ ). 
wich porous structure was $1.78 \mathrm{MPa}$, which was $43.0 \%$ higher than that of ultra-stable foamed concrete $(1.25$ $\mathrm{MPa})$. The 28 days flexural strength of sandwich porous structure $(2.18 \mathrm{MPa})$ was approximately $65.6 \%$ higher than that of ultra-stable foamed concrete $(1.31 \mathrm{MPa})$. In the bending test, the maximum stress occurs in the midspan, and the stress distribution in the cross section was large in the outer layer and small in the middle layer. Due to the higher flexural strength of the polymer modified cement paste in comparison to the ultra-stable foamed concrete, this thin layer could withstand higher stress, leading to the drastically enhancement of the flexural strength for sandwich porous structure. The failure mode of the sandwich porous structure is related to the bond behavior of the interface. In the three-point bending test, when the interface is generally bonded (Fig. 7a), the interface is weak and easily cracked when carrying load, resulting in the failure of the whole structure (Fig. 7b). And when the interface is tightly bonded (Fig. 7c), the failure mode is the middle fracture of the specimen, which means that the interface can bear higher load and enhances the final strength of the sandwich structure (Fig. 7d). In addition, the ultra-stable foamed concrete would reduce the dead weight. Thus, the light weight and high strength performance was achieved through the sandwich porous structure. The design of sandwich porous structure greatly improves the flexural strength of lightweight foamed concrete structure.

\subsection{Water absorption}

Water absorption experiments were carried out after 28 days curing, and the results were shown in Fig. 8. The water absorption rate of UFC-750 and SPS was $28.97 \%$ and $29.95 \%$, respectively. The results show that the resistance of sandwich porous structure to water absorption is almost not decreased, because the outer layer of polymer modified cement paste of sandwich porous structure is resistant to water entry. The existence of polymer can compact the pore structure of the cement paste and restrict the penetration of water, which is contributed to improving the water resistance of the structure.

\subsection{Thermal conductivity}

PMC, UFC-500 and UFC-750 dried after curing for 28 days were tested by thermal conductivity tester, respec- tively. The results demonstrated that the thermal conductivity of PMC was $0.8478\left(W \cdot \mathrm{m}^{-1} \cdot \mathrm{K}^{-1}\right)$, UFC-500 was $0.1533\left(W \cdot m^{-1} \cdot K^{-1}\right)$, and UFC-750 was $0.2015(W$. $\left.m^{-1} \cdot K^{-1}\right)$. The composite thermal conductivity of SPS was calculated by series model mentioned in section 2.3.6. The thickness of PMC is $5 \mathrm{~mm}$, and that of UFC-500 is $30 \mathrm{~mm}$. If the parameters are substituted into the formula of composite thermal conductivity, then

$$
\begin{aligned}
& \delta_{1}=5 \mathrm{~mm}, K_{1}=0.8478\left(\mathrm{~W} \cdot \mathrm{m}^{-1} \cdot \mathrm{K}^{-1}\right) ; \\
& \delta_{2}=30 \mathrm{~mm}, K_{2}=0.1533\left(\mathrm{~W} \cdot \mathrm{m}^{-1} \cdot \mathrm{K}^{-1}\right) ; \\
& \delta_{3}=5 \mathrm{~mm}, K_{3}=0.8478\left(\mathrm{~W} \cdot \mathrm{m}^{-1} \cdot \mathrm{K}^{-1}\right) .
\end{aligned}
$$

Calculate the thermal resistance $R_{i}$ of monolayer structure

$$
\begin{aligned}
& R_{1}=\delta_{1} / K_{1}=5 / 0.8478=5.8976\left(K \cdot \mathrm{m}^{2} \cdot \mathrm{W}^{-1}\right) \\
& R_{2}=\delta_{2} / K_{2}=30 / 0.1533=195.6947\left(\mathrm{~K} \cdot \mathrm{m}^{2} \cdot \mathrm{W}^{-1}\right) \\
& R_{3}=\delta_{3} / K_{3}=5 / 0.8478=5.8976\left(\mathrm{~K} \cdot \mathrm{m}^{2} \cdot \mathrm{W}^{-1}\right)
\end{aligned}
$$

The total thermal resistance $R$ is

$$
\begin{aligned}
R=\sum_{i=1}^{3} R_{i} & =R_{1}+R_{2}+R_{3}=5.8976+195.6947+5.8976 \\
& =207.4899\left(\mathrm{~K} \cdot \mathrm{m}^{2} \cdot \mathrm{W}^{-1}\right)
\end{aligned}
$$

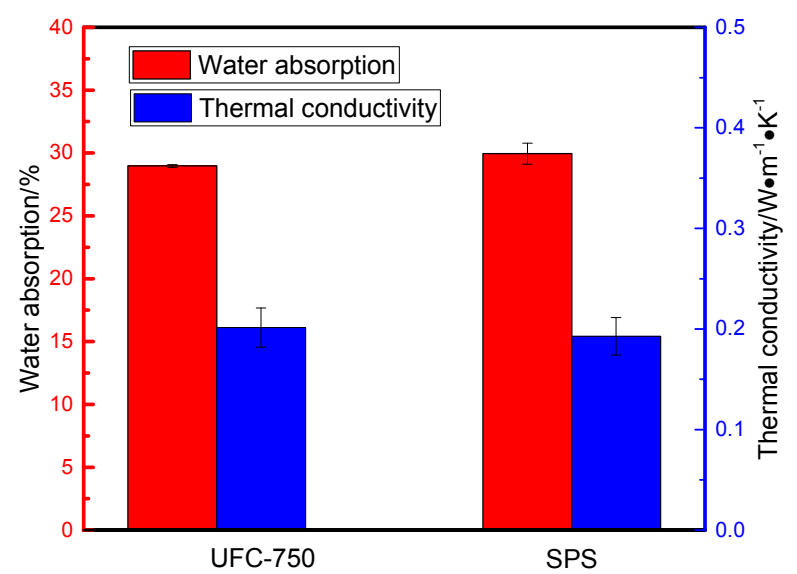

Fig. 8 Water absorption and thermal conductivity of the sandwich porous structure. UFC-750 = Ultra-stable Foamed Concrete (density: $750 \mathrm{~kg} / \mathrm{m}^{3}$ ); SPS= Sandwich Porous Structure (density: $750 \mathrm{~kg} / \mathrm{m}^{3}$ ).
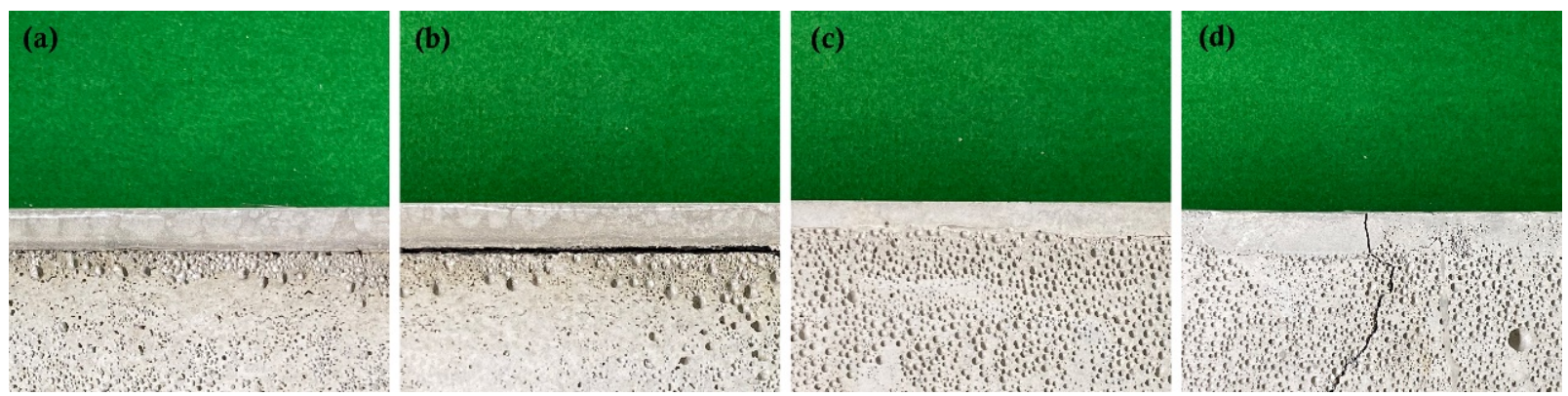

Fig. 7 The bond behavior and failure mode of the sandwich porous structure. 
The thermal conductivity of SPS is

$$
K_{s}=\frac{\delta}{R}=\frac{\sum_{i=1}^{3} \delta_{i}}{\sum_{i=1}^{3} R_{i}}=\frac{40}{207.4899}=0.1927\left(\mathrm{~K} \cdot \mathrm{m}^{-1} \cdot \mathrm{W}^{-1}\right)
$$

After the calculation based on the model, the thermal conductivity of SPS was $0.1927\left(\mathrm{~W} \cdot \mathrm{m}^{-1} \cdot \mathrm{K}^{-1}\right)$, which was slightly smaller than that of UFC-750, as illustrated in Fig. 8. Because the middle layer of sandwich porous structure adopted UFC-500, which had better insulation performance, and the thickness of UFC-500 made the overall insulation performance of sandwich porous structure better.

\section{Conclusions}

The mechanical and physical properties of SPS and UFC were investigated. The main conclusions were as follows:

It was feasible to select polymer modified cement paste and ultra-stable foamed concrete to fabricate a new sandwich porous structure. Layered pouring can make the interface between different layers closely fit. In order to maximize the ratio of overall stiffness to weight, the thickness relationship between surface layer and inner core was $1: 6$. Compared with ultra-stable foamed concrete under the same density, the flexural strength of sandwich porous structure showed a $43.0 \%$ increase in 7 -day and $65.6 \%$ increase in 28 -day. The thermal conductivity of the sandwich porous structure was calculated using the series model, and the results showed that the insulation performance of the sandwich porous structure was slightly better than that of the ultra-stable foamed concrete with the same density. The water absorption rate was similar for the ultra-stable foamed concrete and the novel foam concrete structure with sandwich porous structure.

\section{Acknowledgements}

This work was funded by The Science and Technology Development Fund, Macau SAR (File no. 078/2017/A2); Multi-Year Research Grant (File no. MYRG2019-00118IAPME, MYRG2019-00135-IAPME), and Research \& Development Grant for Chair Professor (File no. CPG202100025-IAPME) from University of Macau.

\section{Reference}

Arunkumar, M. P., Pitchaimani, J., Gangadharan, K. V. and Lenin Babu, M. C., (2017). "Sound transmission loss characteristics of sandwich aircraft panels: Influence of nature of core." Journal of Sandwich Structures \& Materials, 19(1), 26-48.

Bach, M. R., Chalivendra, V. B., Alves, C. and Depina, E., (2017). "Mechanical characterization of natural biodegradable sandwich materials." Journal of Sandwich Structures and Materials, 19(4), 482-496.

Birman, V. and Kardomateas, G. A., (2018). "Review of current trends in research and applications of sandwich structures." Composites Part B: Engineering, 142, 221-240.

Chen, P.-Y., McKittrick, J. and Meyers, M. A., (2012). "Biological materials: Functional adaptations and bioinspired designs." Progress in Materials Science, 57(8), 1492-1704.

Cherniaev, A. and Telichev, I., (2017). "Weight-efficiency of conventional shielding systems in protecting unmanned spacecraft from orbital debris." Journal of Spacecraft and Rockets, 54(1), 75-89.

China JG/T 266-2011, (2011). "Foamed concrete (JG/T 266-2011)." Republic of China. Beijing: Standardization Administration of China. (in Chinese)

Chróścielewski, J., Miśkiewicz, M., Pyrzowski, Ł., Sobczyk, B. and Wilde, K., (2017). "A novel sandwich footbridge - Practical application of laminated composites in bridge design and in situ measurements of static response." Composites Part B: Engineering, 126, 153-161.

Eltayeb, E., Ma, X., Zhuge, Y., Youssf, O. and Mills, J. E., (2020). "Influence of rubber particles on the properties of foam concrete." Journal of Building Engineering, 30, 101217.

Falliano, D., De Domenico, D., Ricciardi, G. and Gugliandolo, E., (2019). "Compressive and flexural strength of fiber-reinforced foamed concrete: Effect of fiber content, curing conditions and dry density." Construction and Building Materials, 198, 479-493.

Gibson, L. J., (2005). "Biomechanics of cellular solids." J Biomech, 38(3), 377-399.

Hopkins, P. M., Norris, T. and Chen, A., (2017). "Creep behavior of insulated concrete sandwich panels with fiber-reinforced polymer shear connectors." Composite Structures, 172, 137-146.

Huebsch, N. and Mooney, D. J., (2009). "Inspiration and application in the evolution of biomaterials." Nature, 462(7272), 426-432.

Lee, Y.-M., Yang, R.-B. and Gau, S.-S., (2006). “A generalized self-consistent method for calculation of effective thermal conductivity of composites with interfacial contact conductance." International Communications in Heat and Mass Transfer, 33(2), 142-150.

Li, Y., Wang, P. and Wang, Z., (2017). "Evaluation of elastic modulus of cement paste corroded in bring solution with advanced homogenization method." Construction and Building Materials, 157, 600-609.

Liu, D. Z. and Tian, S. H., (2012). "The experimental research of new lightweight steel composite slab." In L. Xie, Ed., Applied Mechanics and Civil Engineering Ii (Vol. 188, pp. 157-161). Stafa-Zurich: Trans Tech Publications Ltd.

Liu, Q., Liu, W., Li, Z., Guo, S. and Sun, G., (2020). "Ultra-lightweight cement composites with excellent flexural strength, thermal insulation and water resistance achieved by establishing interpenetrating network." Construction and Building Materials, 250, 118923. 
Lura, P., Jensen, O. M. and Van Breugel, K., (2003). "Autogenous shrinkage in high-performance cement paste: An evaluation of basic mechanisms." Cement and Concrete Research, 33(2), 223-232.

Meshgin, P. and Xi, Y., (2013). "Multi-scale composite models for the effective thermal conductivity of PCM-concrete." Construction and Building Materials, 48, 371-378.

Meyers, M. A., Chen, P.-Y., Lin, A. Y.-M. and Seki, Y., (2008). "Biological materials: Structure and mechanical properties." Progress in Materials Science, 53(1), 1-206.

Nan, C.-W., Birringer, R., Clarke, D. R. and Gleiter, H., (1997). "Effective thermal conductivity of particulate composites with interfacial thermal resistance." Journal of Applied Physics, 81(10), 6692-6699.

Pascual, C., Montali, J. and Overend, M., (2017). "Adhesively-bonded GFRP-glass sandwich components for structurally efficient glazing applications." Composite Structures, 160, 560-573.

Qu, H., Zhang, J., Du, A., Chen, B., Chai, J., Xue, N. and Cui, G., (2018). "Multifunctional sandwich-structured electrolyte for hgh-performance lithium-sulfur batteries." Adv Sci (Weinh), 5(3), 1700503.

Rasa, E., Ketabchi, H. and Afshar, M. H., (2009). "Predicting density and compressive strength of concrete cement paste containing silica fume using artificial Neural Networks." Scientia Iranica, 16(1), 33-42.

Sennewald, C., Kaina, S., Weck, D., Gruhl, A., Thieme, M., Hoffmann, G. and Hufenbach, W. A., (2014). "Metal sandwiches and metal-matrix-composites based on 3D woven wire structures for hybrid lightweight construction." Advanced Engineering Materials, 16(10), 1234-1242.

Soleimanzadeh, S., (2013). "Influence of high temperatures on flexural strength of foamed concrete containing fly ash and polypropylene fiber." International Journal of Engineering, 26(2 (B)), 117-126.

Sun, C., Zhu, Y., Guo, J., Zhang, Y. and Sun, G., (2018a). "Effects of foaming agent type on the workability, drying shrinkage, frost resistance and pore distribution of foamed concrete." Construction and Building
Materials, 186, 833-839.

Sun, Y., Guo, L.-C., Wang, T.-S., Zhong, S.-Y. and Pan, H.-Z., (2018b). "Bending behavior of composite sandwich structures with graded corrugated truss cores." Composite Structures, 185, 446-454.

Tabatabaiefar, H. R., Mansoury, B., Khadivi Zand, M. J. and Potter, D., (2017). "Mechanical properties of sandwich panels constructed from polystyrene/cement mixed cores and thin cement sheet facings." Journal of Sandwich Structures \& Materials, 19(4), 456-481.

Taoukil, D., El bouardi, A., Sick, F., Mimet, A., Ezbakhe, H. and Ajzoul, T. (2013). "Moisture content influence on the thermal conductivity and diffusivity of wood-concrete composite." Construction and Building Materials, 48, 104-115.

Tummala, V. S., Mian, A., Chamok, N. H., Poduval, D., Ali, M., Clifford, J. and Majumdar, P., (2017). "Three-dimensional printed dielectric substrates for radio frequency applications." Journal of Electronic Packaging, 139(2), 020904.

Xiong, J., Du, Y., Mousanezhad, D., Eydani, A. M., Norato, J. and Vaziri, A., (2019). "Sandwich structures with prismatic and foam cores: A review." Advanced Engineering Materials, 21(1), 1800036.

Xiong, J., Mines, R., Ghosh, R., Vaziri, A., Ma, L., Ohrndorf, A. and Wu, L., (2015). "Advanced micro-lattice materials." Advanced Engineering Materials, 17(9), 1253-1264.

Zeng, Z., Gai, L., Petitpas, A., Li, Y., Luo, H., Wang, D. and Zhao, X., (2017). "A flexible, sandwich structure piezoelectric energy harvester using PIN-PMN-PT/epoxy 2-2 composite flake for wearable application." Sensors and Actuators A: Physical, 265, 62-69.

Zhang, Z. and Wang, H., (2016). "The pore characteristics of geopolymer foam concrete and their impact on the compressive strength and modulus." Frontiers in Materials, 3, 38.

Zheng, H. F., Forgetta, V., Hsu, Y. H., Estrada, K., Rosello-Diez, A., Leo, P. J. and Richards, J. B., (2015). "Whole-genome sequencing identifies EN1 as a determinant of bone density and fracture." Nature, 526(7571), 112-117. 